\title{
Factors associated with adherence to iron folate supplementation among pregnant women in West Dembia district, northwest Ethiopia: a cross sectional study
}

\author{
Tsegaye Molla', Tadesse Guadu², Esmael Ali Muhammad and Melkamu Tamir Hunegnaw ${ }^{3 *}$
}

\begin{abstract}
Objective: In Ethiopia, iron folate tablets are prescribed for all pregnant mothers during their antenatal visits and given for free; however, only limited data are available on their adherence. Therefore, the aim of this study was to assess adherence to iron folate supplementation and its associated factors among pregnant women in West Dembia district, northwest Ethiopia. An institution based cross-sectional study was conducted on 348 pregnant women that had at least one antenatal care visit. Bivariate and multivariate logistic regressions were employed to identify the predictors at $p$-value $<0.2$ and 0.05 respectively.

Results: Adherence to iron folate supplementation in this study was 52.9\% [95\% Cl (47.7, 58.0\%)]. Women who had good knowledge about anemia (AOR: $2.63,95 \% \mathrm{Cl} 1.51,4.59$ ), knowledge about iron folate supplementation (AOR: $2.82,95 \% \mathrm{Cl} 1.52-5.23$ ), four and more ANC visits (AOR: 6.97, 95\% Cl 3.25, 14.96), and anemia history during current pregnancy (AOR: $13.87,95 \% \mathrm{Cl} 3.75,51.35$ ) were significantly associated with adherence to iron folate supplementation. Therefore, preventing prenatal anemia, improving knowledge of women about anaemia and iron folate supplementation, and increasing ANC services are essential to increase adherence.
\end{abstract}

Keywords: Adherence, Iron folate supplementation, Pregnant women, Ethiopia

\section{Introduction}

Globally, $41.8 \%$ of pregnant women are anemic, half of the burden being due to iron deficiency [1]. Iron deficiency anemia aggravates maternal blood loss and infections at childbirth; and it is also associated with increased prenatal mortality and morbidity contributing to low birth weight, lowered resistance to infections, poor cognitive development, reduced work capacity, and a significant impact on economic growth and development [2,3].

Iron deficiency anemia, which occurs due to an increased requirement of iron folate, is common during pregnancy [4]. Supplementation has been a major

\footnotetext{
*Correspondence: melkamutamir@gmail.com

${ }^{3}$ Department of Human Nutrition, Institute of Public Health, College of Medicine and Health Sciences, University of Gondar, P.o.box.196, Gondar, Ethiopia

Full list of author information is available at the end of the article
}

strategy in low and middle-income countries to reduce iron deficiency anemia during pregnancy. The recommended daily dose is $30-60 \mathrm{mg}$ of elemental iron and $400 \mu \mathrm{g}$ of folic acid [5]. A study suggested that iron folate supplementation would increase the mean hemoglobin concentration of pregnant women by $10.2 \mathrm{~g} / \mathrm{l}$ by eliminating about $50 \%$ of anemia [6].

Even though, pregnant women in Ethiopia take a daily oral iron folate supplements as part of the ANC, the prevalence of anemia increased from $22 \%$ in 2011 to $29 \%$ in 2016 [7]. WHO and the Ethiopian National Nutrition Program recommend iron folate tablets for all pregnant women, but the magnitude of adherence is still within the range of $20.4 \%$ [8] to $70 \%$ [9], which is quite low.

The variation and magnitude of adherence is influenced by multiple factors, like socio-demographic, ANC visits, nutrition counseling, and knowledge about anemia as well as iron folate supplementation [10-12]. Improving 
adherence is therefore essential for eliminating anaemia and to make iron supplementation programs successful. Therefore, this study was done to determine adherence and associated factors relating to iron folate supplementation among pregnant women in Dembia district northwest, Ethiopia.

\section{Main text \\ Methods and materials \\ Study setting}

A facility based cross-sectional study was conducted to determine the adherence and associated factors of iron folate supplementation among pregnant women in West Dembia district, northwest Ethiopia, 2018. The district is located in Central Gondar Zone, Amhara Region about $245 \mathrm{~km}$ from Bahir Dar. The total population of the district is 131,412 of which $23.58 \%$ are in the reproductive age group. Nearly, 4428 women are expected to get pregnant within a year. The district has five public health centers which give comprehensive ANC and maternal health care services.

\section{Sample size and sampling method}

The sample size was calculated by using the single population proportion formula. The magnitude of adherence to iron folate supplementation was $28.9 \%$ [13], with a precision of $5 \%$ and $95 \%$ CI. The sample size 316 , became 348 after adding, a $10 \%$ non response rate.

All health centers in the district were included in the study, and the number of participants per health center was allocated based on the average number of pregnant women who visit each health center per month. Previous ANC follow ups per month for Abawram, Abrjha, Chuhait, Gorgora, Sankisa health centers were 161, 128, 266,26 , and 185, respectively. Based on this data and the sample size of the study, the participants of each health center were selected using a systematic random sampling method with intervals of two.

\section{Data collection and analysis}

The data collection instruments were close-ended questions, and questionnaire contiens included socio-demographic, obstetric history, knowledge about anemia, and iron folate supplementation related variables. The pregnant women who took iron folate tablets at least 4 days in recent weeks were considered to have adhered to the supplementation [14].

The questionnaire was pretested on 34 pregnant women of similar population in East Dembia district, Koladiba health center. Data were collected and supervised by five diploma and two BSc nurses degree graduate nurses, respectively. Both data collectors and supervisors were trained on how to collect the data and how to use the data collection instruments. The supervisors checked the completeness of the data every day.

The collected data were entered, coded and cleaned, using Epi INFO version 7.0, and data management and analyses were performed using SPSS version 20.0 software. Socio-demographic, obstetric, and medical history of pregnant women were presented in texts and tables. Bivariate analysis was done and variables with less than $0.2 \mathrm{p}$-values were included in the multiple logistic regression analysis. In the multivariate analysis, predictors with $\mathrm{p}<0.05$ were considered statistically significant.

\section{Results}

Socio-demographic characteristics of the study subjects

A total of 348 pregnant women that had at least one antenatal care visit were interviewed with a response rate of $100 \%$. The mean age of the participants was 26.86 years ( \pm 5.78 standard deviations) with a minimum and maximum of 18 and 46 years respectively. Two hundred seventy-one (77.9\%) were rural dwellers. Most of the participants, 339 (97.4\%), were Orthodox Christians and 334 (96\%) were married. Regarding educational status, $193(55.5 \%)$ were unable to read and write. One hundred thirty-six (39.1\%) and 134 (38.5\%) were farmers and housewives, respectively (Table 1 ).

\section{Adherence to iron folate supplementation}

In this study, adherence to iron folate supplementation among pregnant women was $52.9 \%$ with $95 \%$ CI (47.7, $58.0)$.

\section{Health and health service related characteristics}

Most of the participants, 262 (75.3\%), were multi gravid, and $62(17.8 \%)$ pregnant women had four and above ANC visits during pregnancy. Only 10 (2.9\%) of the participants had hypertension in the current pregnancy, 21 (6\%) infected by malaria, and $2(0.6 \%)$ had other complications. About $57.5 \%$ and $68.7 \%$ of the participants had good knowledge about anemia and good iron folate supplementation, respectively. The main reasons for non-adherence to iron folate supplementation were forgetfulness $(41 \%)$, fear of side effect $(40 \%)$, and fear of increased baby size (29\%) (Table 2).

\section{Factors associated with adherence to iron folate supplementation}

Binary logistic regression was carried out to determine factors associated with adherence to iron folate supplementation. In the multivariate logistic regression analysis, ANC visits, anemia before this pregnancy, prenatal knowledge about anemia, and iron folate supplementation were found to be statistically significantly associated 
Table 1 Socio- demographic characteristics of pregnant women in West Dembia northwest Ethiopia $2018(\mathrm{~N}=348)$

\begin{tabular}{llrr}
\hline Characteristics & Category & Frequency & Percentage \\
\hline Age in years & $15-24$ & 117 & 33.6 \\
& $25-34$ & 189 & 54.3 \\
\multirow{4}{*}{ Religion } & $\geq 34$ & 42 & 12.1 \\
\multirow{4}{*}{ Residence } & Orthodox & 339 & 97.4 \\
& Muslim & 9 & 2.6 \\
Educational status & Rural & 271 & 77.9 \\
& Urban & 77 & 22.1 \\
& Wnable to read and & 193 & 55.5 \\
& Able to read and write & 69 & 19.8 \\
& Elementary completed & 34 & 9.8 \\
& Secondary completed & 27 & 7.8 \\
& College and above & 25 & 7.2 \\
Marital status & Married & 334 & 96.0 \\
& Single & 14 & 4.0 \\
Monthly income in & $<1000$ & 31 & 89.0 \\
Ethiopian Birr & 1000-3000 & 258 & 74.1 \\
& $>3000$ & 59 & 17.0 \\
Current occupation & Farmer & 136 & 39.1 \\
& Housewife & 134 & 38.5 \\
& Daily laborer & 10 & 2.9 \\
& Merchant & 32 & 9.2 \\
& Government employee & 33 & 9.5 \\
& Privet employee & 3 & 0.9 \\
\hline
\end{tabular}

with adherence to iron folate supplementation for pregnant women at a $95 \% \mathrm{CI}$ and a p-value of 0.05 .

According to the binary logistic regression model, the odds of adherence to iron folate supplementation 2.6 were more likey among pregnant women who had good knowledge about anemia compare to pregnant women who had poor knowledge (AOR: 2.63, 95\% CI 1.51, 4.59). Good knowledge of iron folate supplementation (AOR: $2.82,95 \%$ CI 1.52, 5.23), four and above ANC visits (AOR: 6.97, 95\% CI 3.25, 14.96), and current pregnancy anemia (AOR: 13.87, 95\% CI 3.75, 51.35) were also significant predictors of adherence to iron folate supplementation for pregnant women (Table 3).

\section{Discussion}

In Ethiopia, all women who seek ANC services from Government health facilities receive iron folate tablets for free. In this study, 52.9\% (95\% CI $(47.7,58.0)$ ) of the pregnant women adhered to iron folate supplementation. This finding was higher than study in Tigray Region, which reported $28.9 \%$ respectively [8]. The finding was however lower than 60.9 and $70.6 \%$ detected in Addis Ababa [15], and Mizan Aman town
[16], Ethiopia, respectively. The justifications for the differences are variations in socio-economic status, descripance in the accessments of health care facilities, dissimilarities in the study periods, and levels of awareness among pregnant women as well as in the availability of iron folate tablets.

In this study, the number of ANC visits was one of the significant predictors of adherence to iron folate supplementation of pregnant women. Women who had four and above ANC visits were significantly associated with adherence to iron folate supplementation compared to women who had less ANC visits. This finding was supported by those of studies done in Tigray Region, Ethiopia, and Indonesia $[13,17]$, respectively. The possible reason might be that when the number of ANC visits increases the opportunity for getting a sufficient number of iron folate tablets also increases. In addition, one of the essential nutrition action contact point is pregnancy. Therefore, during ANC visits, counseling about iron folate supplementation and advice to continue taking iron folate tablets is expected from health workers who give ANC services.

Pregnant women who had good knowledge of anemia were 2.63 times more likely to adhere to iron folate supplementation than their counterparts. This was in line with studies done in Mecha district, west Amhara [18] and rural districts of Ethiopia [19]. This might be due to the fact that when a pregnant woman has knowledge she tends to take iron folate tablets during pregnancy [20].

In this study, knowledge about iron folate supplementation was positively associated with adherence, which was supported by different studies, like in the rural districts of Ethiopia [19], for example, in west Amhara [18] and a study in southeastern Nigeria [21]. This may be probably became pregnant women who have awareness about the importance of iron folate supplementation during pregnancy are more likely to take the tablets than women who have no knowledge.

This study showed that women who had history of anaemia during the then pregnancy were more likely to adhere compared to women who no such knowledge. This finding was similar to those of studies done in Western Amhara, Ethiopia [18] and Tanzania [22]. The reason might be that women who had anemia history took more tablets for fear of side effects, and that health providers gave more emphasis to anaemic clients than to non-anaemic ones.

In this study, the main reason for non-adherence was forgetfulness. Like the results of India [23], a rural district of Ethiopia [19], and south eastern Nigeria [21]. The possible explanation might be that health professionals did not appropriately council about the benefities, side 
Table 2 Obstetrics and medical history of pregnant women in West Dembia northwest Ethiopia 2018 (N=348)

\begin{tabular}{|c|c|c|c|}
\hline Characteristics & Category & Frequency & Percentage \\
\hline \multirow[t]{2}{*}{ Gravidity } & Prim gravid & 262 & 75.3 \\
\hline & Multi gravid & 86 & 24.6 \\
\hline \multirow[t]{3}{*}{ Number of ANC visit } & $\leq 2$ & 163 & 46.8 \\
\hline & 3 & 123 & 35.3 \\
\hline & $\geq 4$ & 62 & 17.8 \\
\hline \multirow[t]{2}{*}{ History of hypertension during current pregnancy } & Yes & 10 & 2.9 \\
\hline & No & 338 & 97.1 \\
\hline \multirow[t]{2}{*}{ History of anaemia during current pregnancy } & Yes & 31 & 8.9 \\
\hline & No & 317 & 91.1 \\
\hline \multirow[t]{2}{*}{ History of malaria attack during current pregnancy } & Yes & 21 & 6.0 \\
\hline & No & 327 & 94.0 \\
\hline \multirow[t]{2}{*}{ Knowledge about anemia } & Poor knowledge & 148 & 42.5 \\
\hline & Good knowledge & 200 & 57.5 \\
\hline \multirow[t]{2}{*}{ Knowledge about iron folate supplementation } & Poor knowledge & 109 & 31.3 \\
\hline & Good knowledge & 239 & 68.7 \\
\hline \multirow[t]{7}{*}{ Reasons for adherence (multiple response possible) } & Advice of health worker & 147 & 90 \\
\hline & Tablets would increase their blood & 39 & 24 \\
\hline & Fear of illness & 28 & 17 \\
\hline & Family support & 24 & 15 \\
\hline & Free in charge & 19 & 12 \\
\hline & Reminding technique & 10 & 6 \\
\hline & Direct consumer advertising & 7 & 4 \\
\hline
\end{tabular}

Table 3 Factors associated with iron folate supplementation adherence among pregnant women in West Dembia northwest Ethiopia 2018 ( $N=348)$

\begin{tabular}{|c|c|c|c|c|}
\hline \multirow[t]{2}{*}{ Characteristics } & \multicolumn{2}{|l|}{ Adherence } & \multirow[t]{2}{*}{ COR $(95 \% \mathrm{Cl})$} & \multirow[t]{2}{*}{$\operatorname{AOR}(95 \% \mathrm{Cl})$} \\
\hline & $\begin{array}{l}\text { Yes } \\
\text { Number (\%) }\end{array}$ & $\begin{array}{l}\text { No } \\
\text { Number (\%) }\end{array}$ & & \\
\hline \multicolumn{5}{|c|}{ Knowledge about anemia } \\
\hline Good knowledge & $80(40.0)$ & $120(60.0)$ & $3.54(2.25,5.57)$ & $2.63(1.51,4.59)^{*}$ \\
\hline Poor knowledge & $104(70.3)$ & $44(29.7)$ & 1 & 1 \\
\hline \multicolumn{5}{|c|}{ Knowledge about iron folate supplementation } \\
\hline Good knowledge & $102(42.7)$ & $137(57.3)$ & $4.08(2.46,6.76)$ & $2.82(1.52,5.23)^{*}$ \\
\hline Poor knowledge & $82(75.2)$ & $27(24.8)$ & 1 & 1 \\
\hline \multicolumn{5}{|l|}{ Number of ANC visit } \\
\hline$\leq 2$ & $105(64.4)$ & $58(35.6)$ & 1 & 1 \\
\hline 3 & $66(53.7)$ & $57(46.3)$ & $1.56(0.97,2.52)$ & $1.32(0.78,2.26)$ \\
\hline$\geq 4$ & $13(21.0)$ & $49(79.0)$ & $6.82(3.42,13.61)$ & $6.97(3.25,14.96)^{*}$ \\
\hline \multicolumn{5}{|l|}{ Previous anemia } \\
\hline Yes & $3(9.7)$ & $28(90.3)$ & $12.42(3.70,41.71)$ & $13.87(3.75,51.35)^{*}$ \\
\hline No & $181(57.1)$ & $136(42.9)$ & 1 & 1 \\
\hline \multicolumn{5}{|l|}{ Previous malaria } \\
\hline Yes & $7(33.3)$ & $14(66.7)$ & $2.36(0.93,5.99)$ & $2.76(0.91,8.39)$ \\
\hline No & $177(54.1)$ & $150(45.9)$ & 1 & 1 \\
\hline \multicolumn{5}{|l|}{ Monthly income } \\
\hline$<37 \$$ & $17(54.8)$ & $14(45.2)$ & 1 & 1 \\
\hline $38-111 \$$ & $109(42.2)$ & $149(57.8)$ & $0.60(0.28,1.27)$ & $0.89(0.37,2.13)$ \\
\hline$>111 \$$ & $38(64.4)$ & $21(35.6)$ & $1.49(0.61,3.61)$ & $1.21(0.43,3.40)$ \\
\hline
\end{tabular}

ANC antenatal care

* Statistically significant at $p<0.05$ after being adjusted for other variables, 1 : reference 
effects, and how to memorize the time for taking iron folate.

\section{Conclusion}

This research showed the level of adherence of pregnant women to iron folate supplementation. The study indicated that there was a low level of adherence to iron folate supplementation among pregnant women who had less than four ANC visits, anemic during the then pregnancy, had poor knowledge about anemia and iron folate supplementation. Therefore, prevention of prenatal anemia, improving knowledge of women about anaemia and iron folate supplementation, and increasing the coverage of ANC services is essential to increase adherence to iron folate supplementation.

\section{Limitations of the study}

The limitation of this study might be under or overestimation of the proportion of adherence and the health conditions of pregnant women because the data were self reported.

\section{Abbreviations}

ANC: antenatal care; EDHS: Ethiopian Demographic and Health Survey; WHO World Health Organization.

\section{Authors' contributions}

$\mathrm{TM}, \mathrm{TG}$, and EAM have substantial contributions to the conception, design and analysis of this work and MTH worked on the interpretation or discussion of results. All authors read and approved the final manuscript.

\begin{abstract}
Author details
1 Amhara Region Central Gondar Health Department Northwest Ethiopia, University of Gondar, P.o.box.196, Gondar, Ethiopia. ${ }^{2}$ Department of Environmental and Occupational Health, College of Medicine and Health Sciences, University of Gondar, P.o.box.196, Gondar, Ethiopia. ${ }^{3}$ Department of Human Nutrition, Institute of Public Health, College of Medicine and Health Sciences, University of Gondar, P.o.box.196, Gondar, Ethiopia.
\end{abstract}

\section{Acknowledgements}

Authors would like to thank University of Gondar for approving ethical clearance. We would like also to thank data collectors, supervisors and study participants.

\section{Competing interests}

The authors declare that they have no competing interests.

\section{Availability of data and materials}

Full data set and materials pertaining to this study can be obtained from corresponding author on reasonable request.

\section{Consent for publication}

Not applicable.

\section{Ethics approval and consent to participate}

Ethical clearance was obtained from Institute of Public Health of the University of Gondar College of Medicine and Health Science. West Dembia district health office gave letter of permission to undertake the study. Informed written consent was obtained from each study participant after explaining the benefits and risks of participating in the study and data were collected after asking the willingness.
Funding

The authors declare that there is no funding source.

\section{Publisher's Note}

Springer Nature remains neutral with regard to jurisdictional claims in published maps and institutional affiliations.

Received: 27 November 2018 Accepted: 2 January 2019

Published online: 06 January 2019

\section{References}

1. Benoist BD, et al. Worldwide prevalence of anaemia 1993-2005: WHO global database on anaemia. Worldwide prevalence of anaemia 1993-2005: WHO global database on anaemia. 2008.

2. Organization, W.H., W.H.O.D.o.R. Health, and W.H.O.R. Health. Pregnancy, childbirth, postpartum, and newborn care: a guide for essential practice. Geneva: World Health Organization. 2003.

3. Tulchinsky TH. Micronutrient deficiency conditions: global health issues. Public Health Rev. 2010;32(1):243.

4. Martí-Carvaja A, et al. Prevalence of anemia during pregnancy: results of Valencia (Venezuela) anemia during pregnancy study. Arch Latinoam Nutr. 2002;52(1):5-11.

5. Organization, W.H. Guideline: daily iron and folic acid supplementation in pregnant women. Geneva: World Health Organization; 2012.

6. Organization W.H. The global prevalence of anaemia in 2011. In: The global prevalence of anaemia in 2011. 2015.

7. ICF, C.S.A.C.E.a. Ethiopia Demographic and Health Survey 2016: Addis Ababa, Ethiopia, and Rockville, Maryland, USA. Fairfax: CSA and ICF; 2016.

8. Taye B, Abeje G, Mekonen A. Factors associated with compliance of prenatal iron folate supplementation among women in Mecha district, Western Amhara: a cross-sectional study. Pan Afr Med J. 2015;20:43. https://doi.org/10.11604/pamj.2015.20.43.4894.

9. Shewasinad S, Negash S. Adherence and associated factors of prenatal iron folic acid supplementation among pregnant women who attend ante natal care in health facility at Mizan-Aman Town, Bench Maji Zone, Ethiopia, 2015. J Pregnancy Child Health. 2017.

10. Jikamo B, Samuel M. Non-adherence to iron/folate supplementation and associated factors among pregnant women who attending antenatal care visit in selected Public Health Institutions at Hosanna Town, Southern Ethiopia, 2016. J Nutr Disord Ther. 2018;8(230):2161-0509.1000230.

11. Birhanu TM, Birarra MK, Mekonnen FA. Compliance to iron and folic acid supplementation in pregnancy, Northwest Ethiopia. BMC Res Notes. 2018;11(1):345.

12. Getachew M, et al. Magnitude and factors associated with adherence to iron-folic acid supplementation among pregnant women in Eritrean refugee camps, northern Ethiopia. BMC Pregnancy Childbirth. 2018;18(1):83.

13. Abel Gebre AM. Assessment of factors associated with adherence to ironfolic acid supplementation among urban and rural pregnant women in North Western Zone of Tigray, Ethiopia: Comparative Study. 2015.

14. Prevention C.f.D.C.a. Pregnancy risk assessment monitoring system (PRAMS), phase 5 standard questions. 2007.

15. Gebreamlak B, Dadi AF, Atnafu A. High adherence to iron/folic acid supplementation during pregnancy time among antenatal and postnatal care attendant mothers in Governmental Health Centers in Akaki Kality Sub City, Addis Ababa, Ethiopia: hierarchical negative binomial poisson regression. PLOS ONE. 2017;12:e0169415.

16. Sisay Shewasinad SN. Adherence and associated factors of prenatal iron folic acid supplementation among pregnant women who attend ante natal care in health facility at Mizan-Aman Town, Bench Maji Zone, Ethiopia. 2015

17. Wiradnyani LAA, et al. Role of family support and women's knowledge on pregnancy-related risks in adherence to maternal iron-folic acid supplementation in Indonesia. Public Health Nutr. 2016;19(15):2818-28.

18. Bekele Taye GA. Factors associated with compliance of prenatal iron folate supplementation among women in Mecha district, Western Amhara: a cross-sectional study, Ethiopia. 2015. 
19. Samson Gebremedhin AS. Coverage, compliance and factors associated with utilization of iron supplementation during pregnancy in eight rural districts of Ethiopia: across-sectional study. 2014.

20. Arega Sadore A, Abebe Gebretsadik L, Aman Hussen M. Compliance with iron-folate supplement and associated factors among antenatal care attendant mothers in Misha District, South Ethiopia: community based cross-sectional study. J Environ Public Health. 2015;2015:781973.

21. Ugwu EO, Olibe AO. Determinants of compliance to iron supplementation among pregnant women in Enugu, Southeastern Nigeria. 2014
22. Ogundipe $\mathrm{O}$, Hoyo C. Factors associated with prenatal folic acid and iron supplementation among 21,889 pregnant women in Northern Tanzania: a cross sectional hospital-based study, Tanzania. BMC Public Health. 2012;12:481.

23. Dutta AJ, Patel PB, Bansal PK. Compliance to iron supplementation among pregnant women: a cross sectional study in urban slum. Natl J Community Med. 2014;5(4):457-62.
Ready to submit your research? Choose BMC and benefit from:

- fast, convenient online submission

- thorough peer review by experienced researchers in your field

- rapid publication on acceptance

- support for research data, including large and complex data types

- gold Open Access which fosters wider collaboration and increased citations

- maximum visibility for your research: over $100 \mathrm{M}$ website views per year

At BMC, research is always in progress.

Learn more biomedcentral.com/submissions 